\title{
Patient-related outcomes of patellofemoral arthroplasty: experience of a single center
}

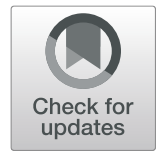

W. Y. M. Abeysekera * (D) and W. Schenk

\begin{abstract}
Purpose: The purpose of this prospective study was to present the experience of a single center on patellofemoral arthroplasty, in terms of patient-related outcomes.

Method: From January 2005 to January 2016, 42 patients with isolated patellofemoral osteoarthritis were treated. The patients were assessed using the Oxford Knee Score preoperatively, and one, five, and eight year(s) after surgery. The data of the patients were analyzed using linear mixed effects models. A $P$ value of 0.05 was considered statistically significant.

Results: Among 42 patients who underwent patellofemoral arthroplasty, only 25 patients (31 limbs involved) had records up to 5 years. There was a significant clinical improvement of Oxford Knee Score postoperatively $(P<0.05)$, lowering the score on average by $10.4 \pm 1.5$ one year after surgery and $8.9 \pm 1.9$ five years after surgery. This improvement was independent of the types of implants $(P>0.05)$, gender $(P>0.05)$, age $(P<0.05)$, and body mass index (BMI) $(P<0.05)$.

Conclusion: Patellofemoral arthroplasty can significantly improve the knee function, and this improvement is independent of the type of implant, gender, age, and BMI. However, further studies will need to assess the longterm outcomes of PFA.
\end{abstract}

Keywords: Patello-femoral arthroplasty, Patello-femoral joint arthritis, Knee joint arthritis, Knee joint arthroplasty

\section{Introduction}

Osteoarthritis of the knee is a condition that causes significant disability. In the United Kingdom, over 300 million pounds is spent annually on knee arthroplasty. Isolated patellofemoral osteoarthritis (PFOA) is detected only 1 in 10 among the population with knee arthritis. These patients are usually relatively young [1].

In the early stages of the disease, there are nonoperative treatments as for any other form of arthritis, but when it becomes severe, an operative approach might be an option. Arthroscopic debridement, patellectomy, total knee arthroplasty (TKA), and isolated patellofemoral arthroplasty (PFA) are the surgical alternatives for PFOA. Since only minimal benefit is attained in severe stages of the osteoarthritis, arthroscopic

\footnotetext{
* Correspondence: yohan.abeysekera@yahoo.com

West Suffolk NHS Trust, Hardwick Ln, Bury St Edmunds, Bury Saint Edmunds IP33 2QZ, UK
}

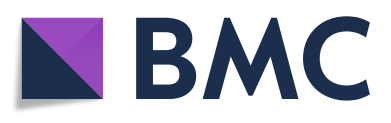

(อ The Author(s). 2021 Open Access This article is licensed under a Creative Commons Attribution 4.0 International License, which permits use, sharing, adaptation, distribution and reproduction in any medium or format, as long as you give

appropriate credit to the original author(s) and the source, provide a link to the Creative Commons licence, and indicate if changes were made. The images or other third party material in this article are included in the article's Creative Commons licence, unless indicated otherwise in a credit line to the material. If material is not included in the article's Creative Commons licence and your intended use is not permitted by statutory regulation or exceeds the permitted use, you will need to obtain permission directly from the copyright holder. To view a copy of this licence, visit http://creativecommons.org/licenses/by/4.0/. surgeries have become less popular, and patellectomy has resulted in poor long-term outcomes. As a result, TKA has become the optimal choice for isolated PFOA [2]. Such choice is further encouraged by the failure of the initial PFAs due to the residual patella malalignment, polyethylene wear, and failure secondary to disease progression of the rest of the knee joint [3]. However, the PFA has several advantages over the TKA for the isolated patellofemoral pathology. PFA allows a speedy recovery following the surgery, because it is a relatively less invasive procedure which preserves the natural ligaments, natural femur and tibia, and nearly normal function of the knee joint [4]. According to a randomized clinical trial evaluating 100 patients, the PFOA patients had a shorter recovery period, a greater range of motion, better physical function scores and less knee pain, compared to their TKA counterparts [5]. 
Recent studies have shown the enhanced outcomes due to better patient selection and more attention paid to soft tissue balancing. Recent developments in implant designs (second-generation PFA) and surgical techniques have also contributed to the significant improvement in short- and medium-term PFA results [6-12]. Athough the survival rates have improved dramatically with novel implants, according to several studies, some patients are still not satisfied with their experience [13].

In this prospective study, we presented the experience in PFA in a single center in terms of patient-related outcomes.

\section{Materials and methods}

From January 2005 to January 2016, 42 consecutive patients with isolated PFOA were treated in our hospital. The inclusion criteria included isolated PFOA with severe discomfort in daily living, such as difficulty in moving up and down on stairs, sitting for a long time, rising from a low chair, and pain at rest. X-ray findings, specifically the level of femorotibial degenerative changes, were determined according to the radiological criteria described by Kellgren et al. [14]. The patients were assessed in terms of the Oxford Knee Score (OKS) preoperatively, and one, five, and eight year(s) after surgery.

All the patients received second-generation PFA implants (symmetric trochlear surface; Avon, Bristol, UK) or (asymmetric trochlear surface; Journey, Smith and Nephew, Memphis, Tennessee, USA). All operations were performed by three different consultant knee surgeons of the same department, but most were performed by the senior surgeon. All surgeons used both types of implants. It was up to the department to decide if to change from Avon to Journey implants, for several logistic and financial reasons.

The limited medial parapatellar approach was used in all cases. None of the surgeons employed the lateral para-patellar approach. Although patella resurfacing was not performed in all TKAs, the patella was resurfaced in all PFAs. We believe this make sense for the treatment of PFOA. In each surgery, apart from the basic arthroplasty principles, the surgeons strictly adhered to the surgical technique as described in the technical guides or instructions provided for the relevant implant. Particular care was taken not to overstuff the patellofemoral joint while achieving the proper patella tracking and patella stability by avoiding a valgus and/or internal rotation of implant components. In order to achieve this, a limited lateral release of the patella was performed in some cases based on the intraoperative assessment. Immediately after surgery, range of movement exercises $\left(0^{\circ}\right.$ to $90^{\circ}$ ) were started as tolerated by the patient, and weight-bearing was restricted for 2 weeks.
In the follow-up study, we assessed surgery-related the general complications, such as urinary or respiratory tract infections, cardiovascular problems, and the complications specifically related to the PFA. The patients were asked to complete a self-reported OKS, which is a validated knee arthroplasty functional outcome measure consisting of 12 items related to the daily activities. The scores range from 12 to 60, with 12 representing the best outcome and 60 the worst outcome [15].

Statistical analysis package $\mathrm{R}$ (version 3.6.0) was used in this study. The data were recorded as mean \pm standard deviation. Paired $t$ tests were used to determine the mean OKS and differences, and the results were presented in bar charts. By using linear mixed effects models, the data of the patients with records up to 5 years $(n=25)$ were applied to estimate the overall OKS change across time and to test the significance of the factors such as the type of implant, age, sex, and body mass index (BMI). A $P$ value of 0.05 was considered statistically significant.

\section{Results}

During the given period, 42 patients underwent PFA. Only 33 patients (39 limbs) had responded to the review. Complete 5-year data were available from 25 patients (involving 31 limbs), and complete 8-year data were available in 6 patients (including 7 limbs). There were 14 left and 17 right knees among 27 females and 4 males. Sequential bilateral PFA were performed in 6 patients. Two types of implants were used, namely, Avon $(n=11)$ and Journey $(n=20)$. Only 2 complications were reported, one requiring a manipulation under anesthesia to overcome knee stiffness while the other needing a patella resurfacing after only the trochlea was resurfaced.

Considering only patients $(n=25)$ who had records up to 5 years, the OKS significantly dropped over time $(P=$ $9.996 \mathrm{e}-13<<0.05)$, lowering the score, on average, by $10.4 \pm 1.5$ one year after surgery and by $8.9 \pm 1.9$ five years after surgery, as estimated by using a linear mixed effects model (Fig. 1). Within each gender group, the OKS decreased after surgery, indicating a clinical improvement. It appeared that this improvement was more prominent in male patients than in female ones. However, the number of male patients was much smaller, and the analysis using the mixed effects models showed that there was no significant difference in the improvement pattern between the male and female patients $(P=$ 0.78) (Fig. 2). The OKS significantly decreased with each type of implant after surgery. Although the mixed effects model analysis $(P=0.58)$ did not show a significant difference between the implants, improvement was more conspicuous with the Journey implants than with the Avon ones (Fig. 3). 


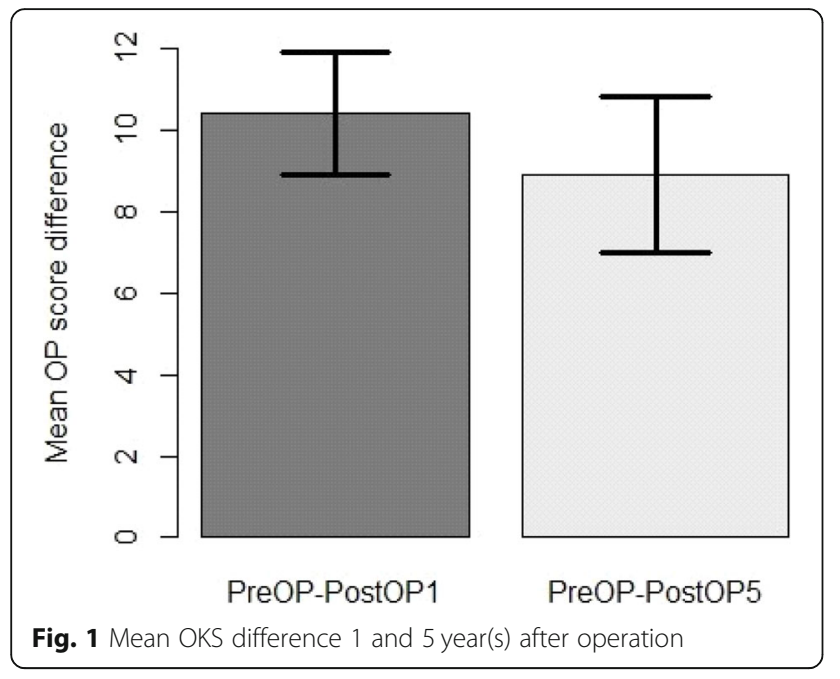

The Avon implant was mostly used in younger patients, and the Journey implant was used in older patients. When the Avon implant was used, the improvement over time was less in older patients compared to younger patients. However, when the Journey implant was used, the improvement over time was more consistent and did not differ much in terms of the age of the patients. Generally, for both implants, the mixed effects analysis showed that improvement in OKS was not dependent on the age of patients $(P=0.85)$ (Fig. 4). In both types of implants, the improvement over time was more obvious in patients with lower BMI. Nonetheless,

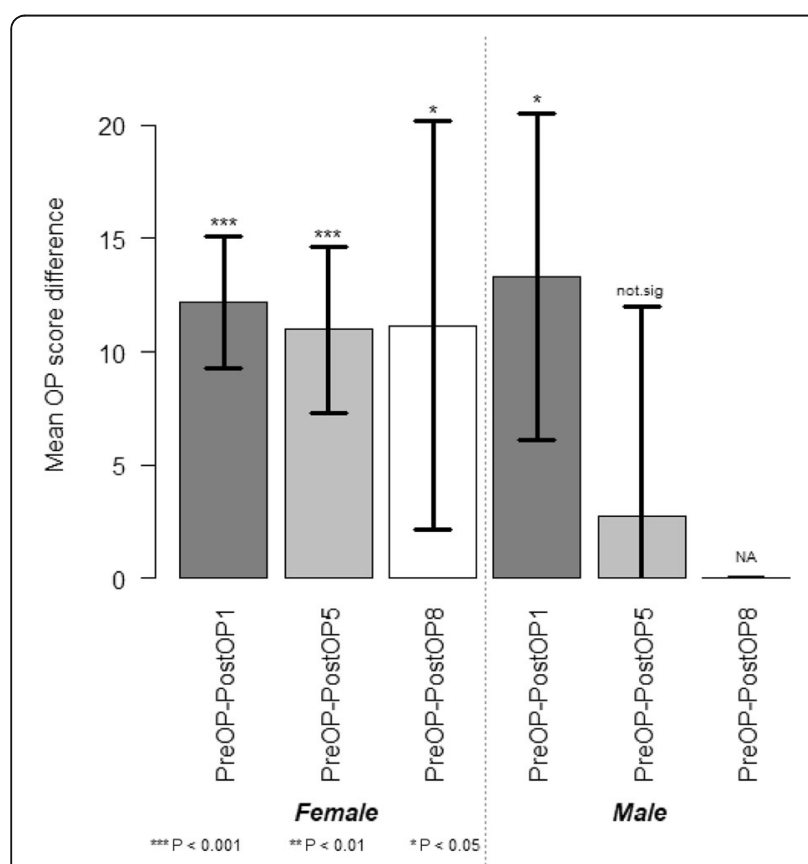

Fig. 2 Mean OKS difference 1,5 and 8 year(s) after operation among males and females

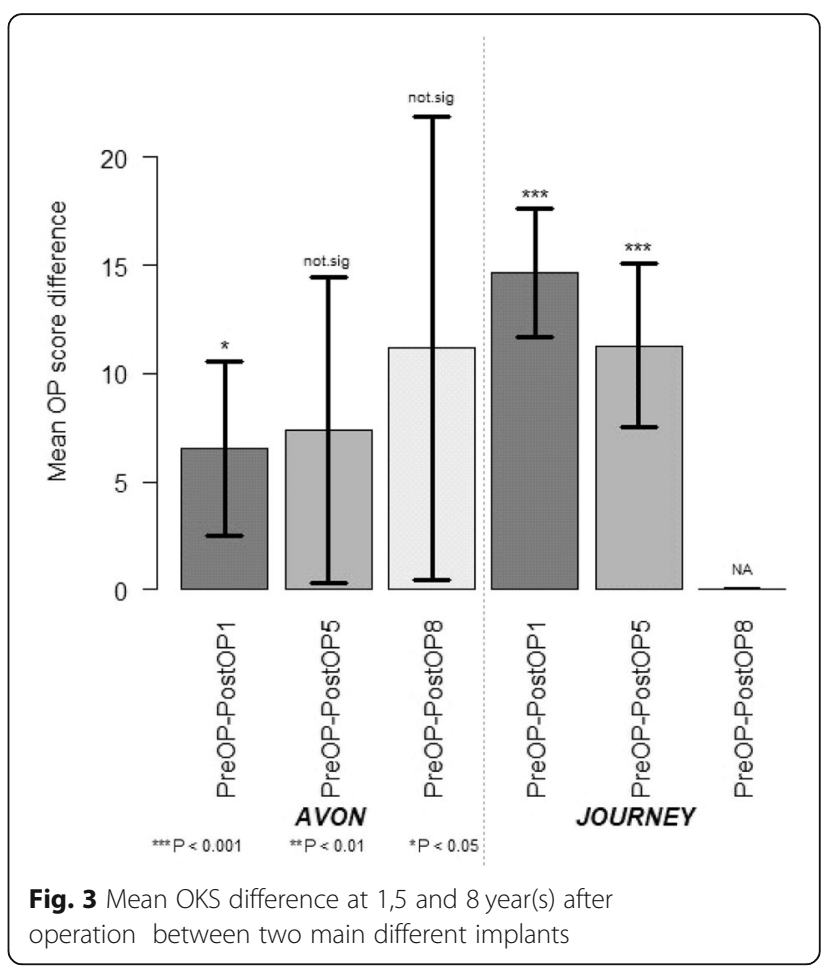

the mixed effects analysis showed that this improvement was no statistically significant $(P=0.11)$ (Fig. 5).

\section{Discussion}

Some studies have shown inconsistent outcomes of PFA, including relatively high failure rates $[6,16-19]$. However, Cartier et al. [20] reported an excellent functional outcome in $77 \%$ of patients after following up a retrospective case series for ten years. Similarly, Odumenya et al. [7] and Stark et al. [21] reported excellent functional outcomes with a $100 \%$ survival rate at 5 and 2 years of follow-ups, respectively. Those findings supported the value of PFA for patients with isolated PFOA. In a recently published systematic review, the overall survival rates of both first- and second-generation PFA implants were $92 \%$ at 5 years, $83 \%$ at 10 years, $75 \%$ at 15 years, and $67 \%$ at 20 years [22], respectively.

Our results showed a short-term improvement of knee function with the use of PFA in the isolated PFOA. It appeared that this improvement was more prominent in male patients than in females. There was a more evident improvement when the Journey implants were used as compared to the Avon. Most studies revealed that neither gender nor age influenced clinical or radiological outcomes [6, 23-25], which is similar to our findings. When the Avon implant was used, the improvement over time was less in older patients compared to younger patients. However, when the Journey implant was used, the improvement over time was more consistent 


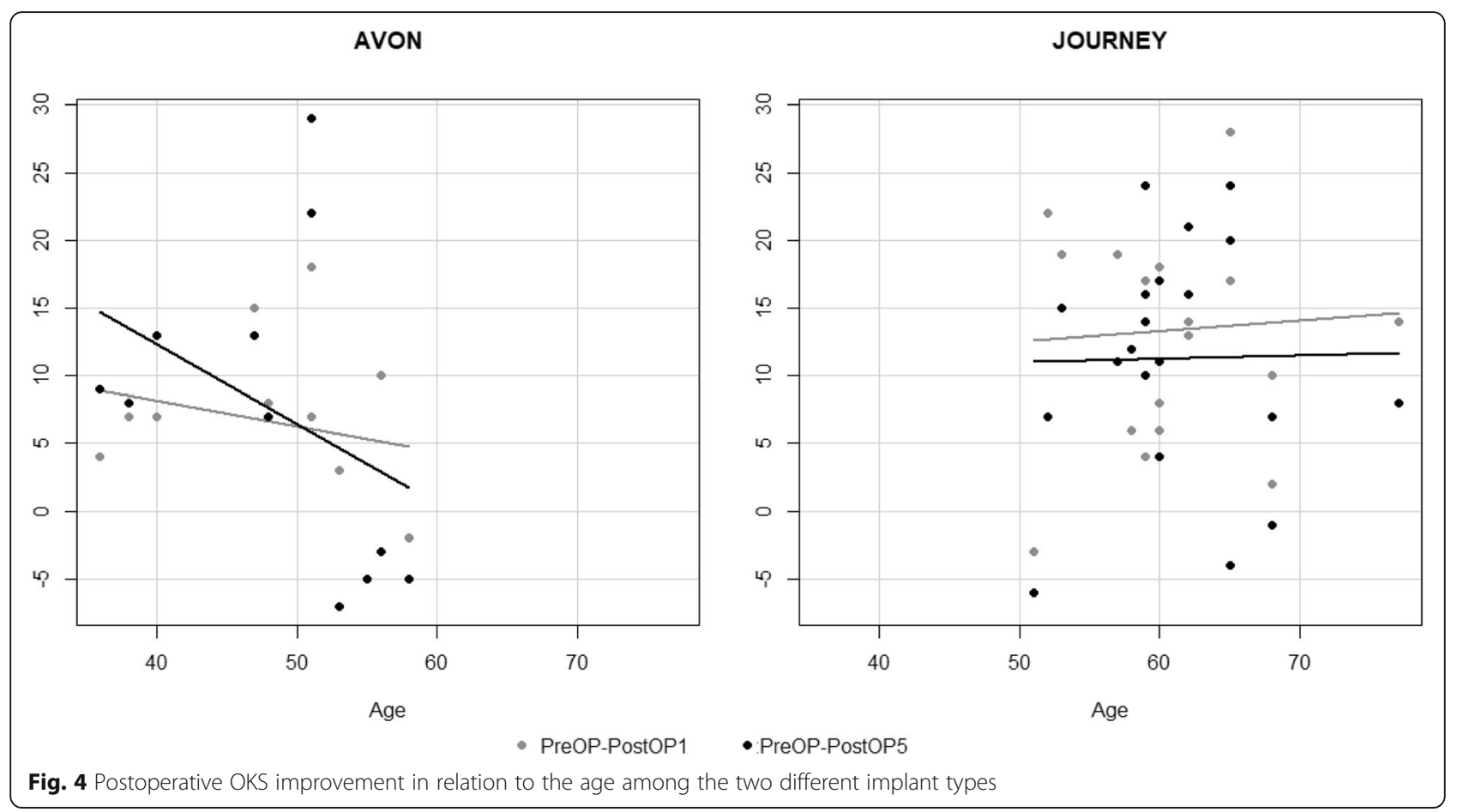

and did not differ much in terms of the age of the patient.

Generally, it is assumed that obesity has a negative effect on the clinical outcomes of TKA [26, 27]. Similarly, a systematic review of 872 knees in 14 eligible studies [28] and another PFA study of 185 knees [6] highlighted a BMI $>30 \mathrm{~kg} / \mathrm{m}^{2}$ as a patient characteristic relating to a poor outcome in PFA. Moreover, in a more recent retrospective study, Liow et al. [29] described a lower patient satisfaction with a slow improvement in functional outcomes in obese patients following PFA. Van Jonbergen et al. [25] reported a higher revision rate in obese

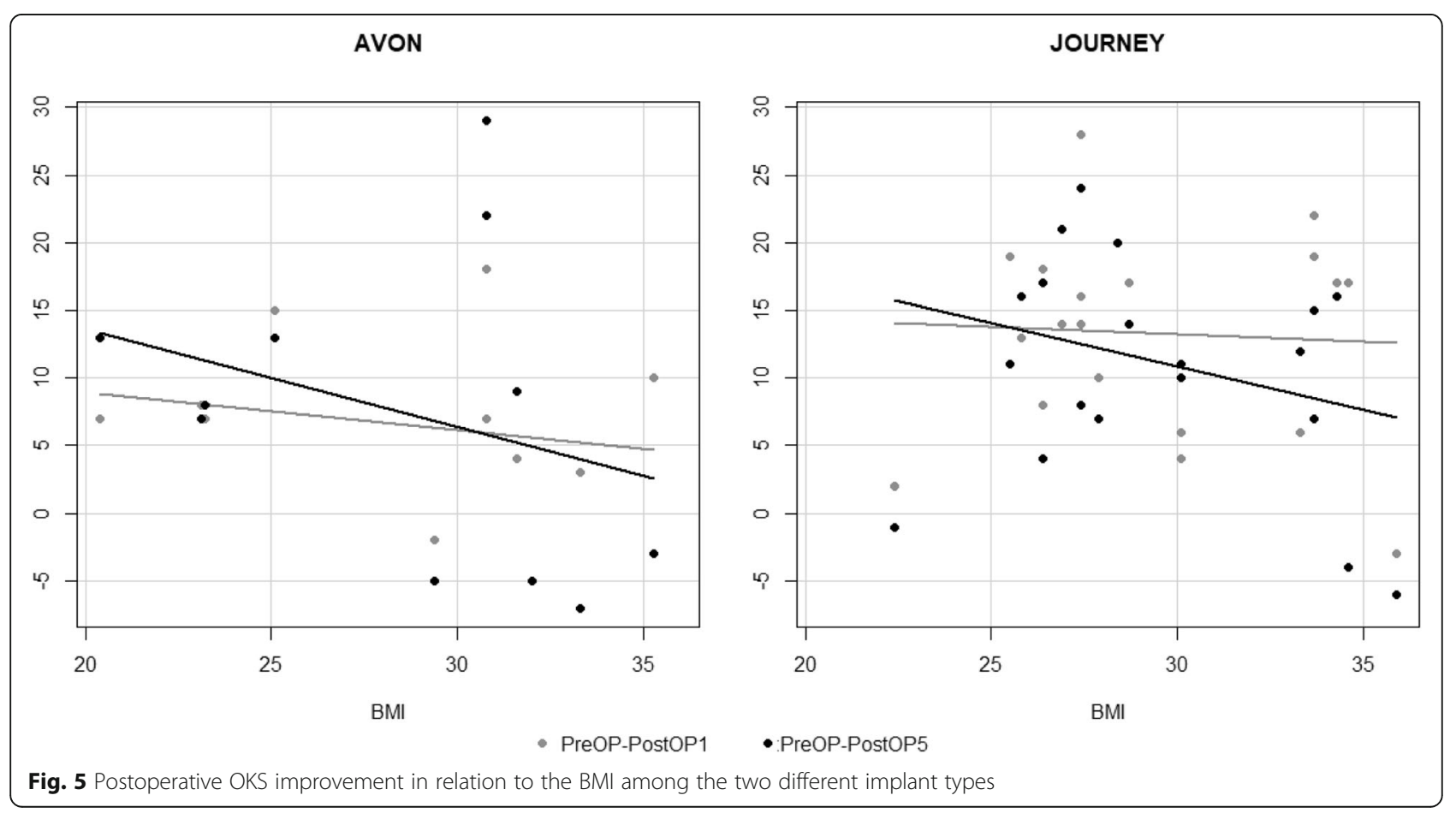


patients. However, we did not find BMI affects the PFA outcomes.

Statistically, the sample size was too small to allow a comparison, which impairs the power of the study and increases the margin of error, which might render the study meaningless. Owing to the inherent features of the retrospective study, the postoperative assessments could not be blinded. In addition, surgeons' preference, experience, and skills might affect the precise evaluation of the effects of the PFA.

\section{Conclusion}

The PFA can significantly improve the knee function, and this improvement is independent of the type of implant, gender, age, and BMI. However further studies are warranted to assess the long-term outcomes of PFA.

\section{Abbreviations}

PFA: Patello-femoral arthroplasty; PFJA: Patello-femoral joint arthritis; OKS: Oxford Knee Score; Post-OP: Postoperative; TKR: Total knee replacement; BMl: body mass index

\section{Acknowledgements}

We are indebted to Mrs. WWM Abeysekera PhD (Stat) MSc (App.Stat) BSc (Stat) Latrobe University, Melbourne, Australia for the invaluable support in statistical advice and analysis.

\section{Authors' contributions}

WYMA: conceptualized the study, collected/analysed data and prepared the manuscript. WS: prepared the manuscript. The authors read and approved the final manuscript.

\section{Funding}

No funding was received for this study.

\section{Availability of data and materials}

The datasets used and/or analyzed during the current study are available from the corresponding author on request.

\section{Ethics approval and consent to participate}

Consent was obtained at the initial preoperative completion of the questionnaire.

\section{Consent for publication}

Informed consent that data will be used for publication was taken from all patients.

\section{Competing interests}

None of the authors have competing interests to declare.

Received: 3 December 2020 Accepted: 12 February 2021

Published online: 03 June 2021

\section{References}

1. Davies AP, Vince AS, Shepstone L, Donell ST, Glasgow MM. The radiologic prevalence of patellofemoral osteoarthritis. Clin Orthop Relat Res. 2002;402: 206-12.

2. Strickland SM, Bird ML, Christ AB. Advances in Patellofemoral Arthroplasty. Curr Rev Musculoskelet Med. 2018;11(2):221-30. https://doi.org/10.1007/s121 78-018-9477-0.

3. Arciero RA, Toomey HE. Patellofemoral arthroplasty. 3-year to 9-year followup study. Clin Orthop Relat Res. 1988;236:60-71.

4. Ackroyd CE. Development and early results of a new patellofemoral arthroplasty. Clin Orthop Relat Res. 2005;436:7-13.

5. Odgaard A, Madsen F, Kristensen PW, Kappel A, Fabrin J. The mark Coventry award: Patellofemoral Arthroplasty results in better range of movement and early patient-reported outcomes than TKA. Clin Orthop Relat Res. 2018; 476(1):87-100. https://doi.org/10.1007/s11999.0000000000000017.

6. Leadbetter WB, Ragland PS, Mont MA. The appropriate use of patellofemoral arthroplasty - an analysis of reported indications, contraindications, and failures. Clin Orthop Relat Res. 2005;436:91-9.

7. Odumenya M, Costa ML, Parsons N, Achten J, Dhillon M, Krikler SJ. The Avonpatellofemoral joint replacement: five-year results from an independent cen-tre. J Bone Joint Surg Br. 2010;92(1):56-60.

8. Nicol SG, Loveridge JM, Weale AE, Ackroyd CE, Newman JH. Arthritis progres-Sion after patellofemoral joint replacement. Knee. 2006;13(4):290-5.

9. Ackroyd CE, Newman JH, Evans R, Eldridge JD, Joslin C. The Avon patellofemoralarthroplasty: five-year survivorship and functional results. J Bone Joint Surg Br. 2007;89(3):310-5.

10. Mont MA, Johnson AJ, Naziri Q, Kolisek FR, Leadbetter WB. Patellofemoralarthroplasty: 7-year mean follow-up. J Arthroplasty. 2012;27(3): 358-61.

11. Akhbari P, Malak T, Dawson-Bowling S, East D, Miles K, Butler Manuel PA. The Avon patellofemoral joint replacement: mid-term prospective results from an independent Centre. Clin Orthop Surg. 2015;7(2):171-6. https://doi. org/10.4055/cios.2015.7.2.171

12. Farr J, Arendt E, Dahm D, Daynes J. Patellofemoral arthroplasty in the athlete. Clin Sports Med. 2014;33(3):547-52. https://doi.org/10.1016/j.csm.2 014.03.003.

13. Kazarian GS, Tarity TD, Hansen EN, Cai J, Lonner JH. Significant functional improvement at 2 years after isolated patellofemoral arthroplasty with an onlay trochlear implant, but low mental health scores predispose to dissatisfaction. J Arthroplasty. 2016;31(2):389-94. https://doi.org/10.1016/j.a rth.2015.08.033.

14. Kellgren JH, Lawrence JS. Radiological assessment of osteoarthritis. Ann Rheum Dis. 1957;16:494-501.

15. Dawson J, Fitzpatrick R, Murray D, Carr A. Questionnaire on the perceptions of patients about total knee replacement. J Bone Joint Surg Br. 1998;80(1):63-9.

16. Hendrix M, Ackroyd CE, Lonner JH. Revision patellofemoral arthro-plasty: three-to seven-year follow-up. J Arthroplasty. 2008;23(7):977-83.

17. van Jonbergen $H$, Werkman DM, Barnaart AF. Dissociation of mobilebearingpatellar component in low contact stress patellofemoral arthroplasty, its mech-anism and management: two case reports. Cases J. 2009;2:7502.

18. Lustig S, Magnussen RA, Dahm DL, Parker D. Patellofemoral arthroplasty, whereare we today? Knee Surg Sports Traumatol Arthrosc. 2012;20(7): $1216-26$.

19. Dy CJ, Franco N, Ma Y, Mazumdar M, McCarthy MM. Gonzalez Della Valle a. complications after patello-femoral versus total knee replacement in the treatment of isolated patello-femoral osteoarthritis. A meta-analysis. Knee Surg Sports Traumatol Arthrosc. 2012;20(11):2174-90. https://doi.org/10.1 007/s00167-011-1677-8.

20. Cartier P, Sanouiller JL, Khefacha A. Long-term results with the first patellotemoral prosthesis. Clin Orthop Relat Res. 2005:436:47-54.

21. Starks I, Roberts S, White SH. The Avon patellofemoral joint replacement independent assessment of early functional outcomes. J Bone Joint Surg Br. 2009;91(12):1579-82

22. van der List JP, Chawla H, Zuiderbaan HA, Pearle AD. Survivorship and functional outcomes of patellofemoral arthroplasty: a systematic review. Knee Surg Sports Traumatol Arthrosc. 2015;25:2622-31. https://doi.org/10.1 007/s00167-015-3878-z.

23. Willekens P, Victor J, Verbruggen D, Vande Kerckhove M, Van Der Straeten C. Outcome of patellofemoral arthroplasty, determinants for success. Acta Orthop Belg. 2015;81(4):759-67.

24. Lustig S, Magnussen RA, Dahm DL, Parker D. Patellofemoral arthroplasty, where are we today? Knee Surg Sports Traumatol Arthrosc. 2012;20(7):1216-26.

25. van Jonbergen HP, Werkman DM, Barnaart LF, van Kampen A. Long-term outcomes of patellofemoral arthroplasty. J Arthroplasty. 2010;25(7):1066-71.

26. Berend KR, Lombardi AV Jr, Mallory TH, Adams JB, Groseth KL. Early failure of minimally invasive unicompartmental knee arthroplasty is associated with obesity. Clin Orthop Relat Res. 2005:440:60-6.

27. Hawker G, Wright J, Coyte P, Paul J, Dittus R, Croxford R, et al. Healthrelated quality of life after knee replacement. J Bone Joint Surg Am. 1998;80(2):163-73.

28. Tarassoli P, Punwar S, Khan W, Johnstone D. Patellofemoral arthroplasty: a systematic review of the literature. Open Orthop J. 2012;6:340-7. 
29. Liow MH, Goh GS, Tay DK, Chia SL, Lo NN, Yeo SJ. Obesity and the absence of trochlear dysplasia increase the risk of revision in patellofemoral arthroplasty. Knee. 2016;23(2):331-7. https://doi.org/10.101 6/j.knee.2015.05.009.

\section{Publisher's Note}

Springer Nature remains neutral with regard to jurisdictional claims in published maps and institutional affiliations.

Ready to submit your research? Choose BMC and benefit from:

- fast, convenient online submission

- thorough peer review by experienced researchers in your field

- rapid publication on acceptance

- support for research data, including large and complex data types

- gold Open Access which fosters wider collaboration and increased citations

- maximum visibility for your research: over $100 \mathrm{M}$ website views per year

At BMC, research is always in progress.

Learn more biomedcentral.com/submissions 